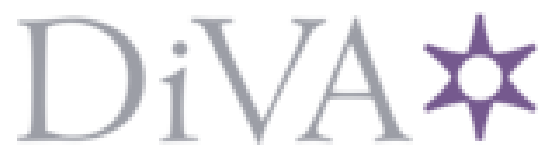

http://www.diva-portal.org

This is the published version of a paper published in Medical and Clinical Research.

Citation for the original published paper (version of record):

Jakobsson, L., Nilsson, P., Fransson, P. (2017)

The influence from sense of coherence on perceived health after prostatectomy: a 5 year follow up.

Medical and Clinical Research, 2(2)

Access to the published version may require subscription.

N.B. When citing this work, cite the original published paper.

Permanent link to this version:

http://urn.kb.se/resolve?urn=urn:nbn:se:hkr:diva-16733 


\title{
The Influence from Sense of Coherence on Perceived Health after Prostatectomy A 5 Year Follow Up
}

\author{
Liselotte Jakobsson $^{1 *}$, Petra Nilsson ${ }^{1}$ and Per Fransson ${ }^{2}$ \\ ${ }^{1}$ Associated professor, RNT, School of Health and Society, \\ Kristianstad University, 28188 Kristianstad, Sweden. \\ *Corresponding author \\ Liselotte Jakobsson, Associated professor, RNT, School of Health \\ and Society, Kristianstad University, 28100 Kristianstad, Sweden, \\ Tel: +46 442040 25; E-mail: Liselotte.Jakobsson@Hkr.se.
}

${ }^{2}$ Associate Professor, Dept. of Nursing, Umeå University, 90187 Umeå, Sweden.

Submitted: 12 Apr 2017; Accepted: 22 Apr 2017; Published: 29 Apr 2017

\begin{abstract}
The purpose of the study was to to describe which factors of health related quality of life were associated with a high sense of coherence in a 5 year perspective. The sense of coherence, SOC-scale, EORTC QLQ C-30 and PR 25 questionnaires were applied to a sample of 222 men at baseline and over 5 years following radical prostatectomy. Result showed significant association to SOC in psychological aspects (emotional and cognitive functioning, $p=<0.00-0.04$ respectively 0.04) and for hormone treatment related symptoms (i.e. manhood $p=<0.05$ ). High SOC was associated with quality of life (index) in the early post treatment period and to aspects of general functioning (role-, emotional- respectively cognitive) in year 3 and 5. High sense of coherence was interpreted to be a health resource for experiencing life quality connected to different aspects at different time points of the data collection. The result showed stability in SOC and QoL scoring over 5 years.
\end{abstract}

Keywords: Prostate Cancer, Longitudinal Study, Sense of Coherence, Quality of Life, Prostate Specific Questionnaire

\section{Background}

The influence of sense of coherence (SOC), on and its connection to generic quality of life (QoL) in men after prostate cancer (PC) treatment is little known from a Swedish perspective. There are PC specific as well as general population study results on quality of life and sense of coherence, however, not presenting SOC as having an influence on QoL [1-3]. By taking a salutogenic approach, turning SOC into a dependent phenomenon with possible impact on QoL and to calculate the chance of having a good life without the risk of having a poor life, it might be possible to get a picture of the post-surgery period from a positive perspective for men surviving curative prostate cancer treatment. Studies have shown that men with long life expectancy benefit from radical treatment even with the presence of erectile dysfunction and urinary leakage, which makes it interesting to look for aspects in life that might contribute not only to long life but also for factors contributing to a good life [4]. Factors that give nourishment to nurse-patient dialogues held at in- and outpatient nursing care units.

$\mathrm{PC}$ is the most common cancer form in Swedish men representing $30.5 \%$ of all male cancer forms in 2013. In Sweden, increased prevalence over several years has been shown to be partly explained by changes in the age structure and partly by improved diagnostic methods. Positively, this up-going trend has stalled during recent years [5]. Thus, many men strive to manage the after effects of PC treatments. Sense of coherence is suggested to be a predominate for how life is managed and is often used as an assessment tool for general health status after treatment or connected to health perception in general. In a population based sample $(n=1715)$ from Sweden, low SOC is found to be related to poor perceived health, low social support and low emotional support [6]. The results were supported by another Swedish study that found low QoL to be connected to low SOC in people of 85 years of age [7]. Both studies give a view of Swedes in general and were not gender or PC specific. Perceived health after PC treatment often show connection to a variety of independent influences. An individual makes use of appropriate combinations of influences, i.e., resources to handle a stressor [8]. Antonovsky presented SOC as a way to explain how an individual makes sense of a stressor in three main stressor types, a permanent state, which characterises a person's life, for example personality and/or delimited life incidents to which individuals do not have an automatic response, for instance becoming seriously ill or failure with a task. This study focuses on a delimited life incident caused by the diagnosis of prostate cancer [9].

It seems logical to assume that a severe diagnosis such as PC may have a negative impact on men's experience of health, on their capacity to handle their situation and to see meaning in their lives. It also seems logical that this opinion may change in a positive direction when the men survive the cancer diagnosis. A longitudinal study is therefore useful for detecting changes over the years. SOC could be a mediating factor towards a greater health experience despite a cancer diagnosis.

SOC has three components describing individual experiences as stressors in relation to perceived capacity in terms of understanding (comprehensibility), ability to use resources (manageability) and personal commitment (meaningfulness). Antonovsky claimed that an individual's state of health is not a dichotomy of health or disease, but a continuum between feeling at ease or dis-ease according to which stressors are met. An individual's position on the continuum is weakened by stressors and strengthened by various resources such as salutogenic components. An individual's degree of SOC can be measured by the SOC scale and a strong 
SOC indicates good ability to manage stressors, where stressors are mainly experienced as positive challenges. The opposite, an individual with a weak SOC has poor ability to handle stressors [9]. Jakobsson et al. (2012), found a stable SOC over three years from a Swedish sample [10]. Whether this is also to be found in a different sample after 5 years is yet to be determined. A hypothesis for this study is that a patient's positive experiences after a treatment process may be regarded as health resources which might render strength in terms of self-efficacy and the will to survive. A longitudinal study makes it possible to follow whether or not that is true for a full study period.

\section{Aim}

The purpose of the study was to describe associations of sense of coherence on quality of life parameters in a 5 year perspective.

\section{Method}

The study was conducted as a longitudinal study of patient' selfreported questionnaire answers. Data was collected at baseline, 3 months, 1, 2, 3 and 5 years (i.e. 2011) after treatment. Medical status was determined at baseline and the men were then regularly followed, over the years by the use of questionnaires.

\section{Patients}

All participating patients were verbally approached by a specialised urological nurse at the first follow up visit after treatment and asked if they wished to participate. They were given written information about the study and gave their verbal and written consent before being given the questionnaire. In all, 222 men accepted to participate. After 5 years 167 men were still in the study $(75.2 \%)$. The questionnaires were answered at home and mailed back in a pre-paid envelope following each data assessment.

\section{Data collection and instruments}

The Orientation to Life questionnaire measuring SOC, with 13 items was used in the study [11]. The scale assesses the components of the sense of coherence concept; comprehensibility, manageability and meaningfulness. The scale's response format ranges from 1 to 7 for each component [11]. Ratings were summarised and a mean value of $\geq 77$ was used for statistical calculation $(=1)$ in order to apply a salutogenic approach over the years. The chance of having a good life was calculated instead of the risk of not having a good life.

The European Organisation for Research and Treatment of Cancer, EORTC, Quality of Life, QLQ C-30 core questionnaire, combined with the module for prostate cancer, PR-25 were applied following treatment $[12,13]$. The QLQ C-30 contains 30 questions and explores functional areas such as physical, role, emotional, cognitive, and social functioning, as well as overall health and quality of life, multi-item scales and single items assessing fatigue, nausea and vomiting, pain, dyspnea, insomnia, appetite loss, constipation and diarrohea and financial impact [12]. High scores represent high functioning in all functioning scales, while low rates in single items represent a high function i.e. few problems. In our study, quality of life is described as an index, QoL, with two variables in the questionnaire and with quality of life as a concept. This might be confusing and should be kept in mind when reading further. The prostate-specific module, PR-25, contains 25 questions and assesses symptoms related to urinary, bowel and hormonal treatment side effects, where higher scores represent more symptoms [13]. In the sexual functioning scale, higher scores represent higher levels of functioning. Cronbach's alpha is described between 0.30 to 0.86 [13]. All variables except single items for QLQ C-30 and PR 25 were transformed into indexes of several variables [14]. Quality of life and PR 25 indexes were used as discrete variables [15].

The study was approved by the Ethical Committee, of the Medical Faculty at Lund University, Sweden (LU451-01).

\section{Analysis}

Variables on nominal and ordinal scale level were tested with the Chi2 test/ANOVA respectively the Mann Whitney U-test [16]. Were a significant difference was detected in mean ratings over the years the Bonferroni post hoc conservative correction was applied [17]. To reduce the number of variables the Pearson correlation coefficient quantified the level of linear relations between the SOC scale, the QLQ C-30 and the PR25. At each time point of the data collection we analysed the relationship between SOC, QLQ C-30 and PR 25 dimensions by the general linear model procedure (SPSS version 18.0). The effect of SOC (dichotomized dependent variable) on QLQ C-30 and PR 25 variables was tested by logistic regression analyses [15]. A p-value of $<0.05$ was considered statistically significant.

\section{Results}

The baseline characteristics of the sample showed a relatively young sample with a mean age of 62 years. All of the participating men were treated with radical prostatectomy and $60 \%$ had a palpable T2 tumour at baseline. PSA levels ranged from 0.4 $34.0 \mathrm{ng} / \mathrm{mil}$ (Table 1). No co- morbidity was assessed. For a detailed presentation of EORTC QLQ C-30 and, PR 25 scores, see Jakobsson \& Fransson, 2013 [18].

Table 1. Characteristics of participants at baseline $(n=222)$.

\begin{tabular}{|c|c|}
\hline Variables & \\
\hline $\begin{array}{c}\text { Age } \\
\text { Year, m, (sd) } \\
\text { Range }\end{array}$ & $\begin{array}{c}62.7(6.09) \\
36-75\end{array}$ \\
\hline $\begin{array}{c}\text { Living with partner }^{1} \\
\text { Yes } \\
\text { No }\end{array}$ & $\begin{array}{c}181 \\
19\end{array}$ \\
\hline $\begin{array}{c}\text { Educational level } \\
<\text { Compulsory school } \\
\text { Compulsory school } \\
\text { Post-Compulsory } \\
\text { below University level } \\
\text { University level } \\
\text { Others }\end{array}$ & $\begin{array}{l}93 \\
48 \\
25 \\
34\end{array}$ \\
\hline $\begin{array}{c}\text { Employment status } \\
\text { Working } \\
\text { Retired } \\
\text { On sick leave } \\
\text { Disability pension } \\
\text { Others }\end{array}$ & $\begin{array}{c}56 \\
86 \\
2 \\
6 \\
7\end{array}$ \\
\hline $\begin{array}{c}\text { Tumour stage } \\
\text { T1 B } \\
\text { T1 C } \\
\text { T2 } \\
\text { T3 }\end{array}$ & $\begin{array}{c}2(1 \%) \\
44(33 \%) \\
73(65 \%) \\
3(1 \%)\end{array}$ \\
\hline
\end{tabular}




\begin{tabular}{|c|c|}
\hline Gleason score & \\
3 & $5(2 \%)$ \\
4 & $24(11 \%)$ \\
5 & $40(18 \%)$ \\
6 & $80(36 \%)$ \\
7 & $60(27 \%)$ \\
8 & $9(4 \%)$ \\
9 & $2(1 \%)$ \\
\hline PSA & \\
Mean & 7.7 \\
Range & $0.4-34.0$ \\
\hline Participants (n) & 222 \\
Baseline & 209 \\
3 months & 197 \\
1 year & 194 \\
2 years & 187 \\
3 years & $167(75.2 \%)$ \\
\hline years & \\
\hline
\end{tabular}

1) Where the figures do not sum up to 222 participants or $100 \%$, there are internal dropouts [18].

The SOC rate was stable over the years with mean ratings at 76.52 to 78.08 and showed no in-group differences $(p=0.953)$ over the years. A value of $\geq 77$ was used as the dependent variable in the following logistic regression analysis. QoL rated as one of 15 indexes (Table 2) scored a mean value of 77.0 - 81.6 with no difference from baseline to the 5 th year $(p=0.165)$. The prostate cancer specific module, PR 25 showed in all a decrease of sexual activity and functioning. Sexual functioning decreased rapidly between 3 months and 1 year $(p=<0.00)$ and 5 years $(p=<0.00)$. More urinary than bowel problems were reported, however, this was only significant for bowel problems after 5 years $(\mathrm{p}=<0.05)$. Hormone related problems increased $(p=<0.00)$ and the use of incontinence aids increased after 3 months but had decreased at 5 years $(\mathrm{ns})$.

Table 2. Logistic regression predicting positive impact from Sense of Coherence $(1=>77.00)$ on Quality of Life parameters (QLQ C-30 and PR 25), 3 months, 1-3 and 5 years post-surgery

\begin{tabular}{|l|c|c|c|c|c|c|c|c|}
\hline Variable & B & S.E. & Wald & $\mathrm{df}$ & $\mathrm{p}$ & $\begin{array}{c}\text { Odds } \\
\text { ratio }\end{array}$ & Lower & Upper \\
\hline
\end{tabular}

3 months $(n=209)$

\begin{tabular}{|c|c|c|c|c|c|c|c|c|}
\hline $\begin{array}{c}\text { Emotional } \\
\text { functioning }\end{array}$ & .05 & .019 & 6.11 & 1 & .01 & 1.04 & 1.01 & 1.09 \\
\hline $\begin{array}{c}\text { Quality of } \\
\text { Life }\end{array}$ & .57 & .02 & 13.50 & 1 & .00 & 1.06 & 1.03 & 1.10 \\
\hline Economy & -.05 & .02 & 5.00 & 1 & .03 & .96 & .92 & 1.02 \\
\hline
\end{tabular}

Year $1(\mathrm{n}=197)$

\begin{tabular}{|c|c|c|c|c|c|c|c|c|}
\hline $\begin{array}{c}\text { Emotional } \\
\text { functioning }\end{array}$ & .04 & .09 & 4.04 & 1 & .04 & 1.04 & 1.00 & 1.07 \\
\hline $\begin{array}{c}\text { Quality of } \\
\text { Life }\end{array}$ & .03 & .02 & 4.01 & 1 & .04 & 1.03 & 1.00 & 1.06 \\
\hline $\begin{array}{l}\text { Hormone } \\
\text { treatment } \\
\text { related } \\
\text { symptoms }\end{array}$ & -.04 & .09 & 3.65 & 1 & .05 & .97 & .93 & 1.00 \\
\hline \hline
\end{tabular}

Year $2(n=194)$

\begin{tabular}{|l|l|l|l|l|l|l|l|l|}
\hline $\begin{array}{l}\text { Emotional } \\
\text { functioning }\end{array}$ & .08 & .03 & 7.62 & 1 & .00 & 1.08 & 1.02 & 1.14 \\
\hline
\end{tabular}

Year $3(n=187)$

\begin{tabular}{|c|c|c|c|c|c|c|c|c|}
\hline $\begin{array}{c}\text { Role } \\
\text { Functioning }\end{array}$ & -.06 & .02 & 5.95 & 1 & .02 & .95 & .90 & .99 \\
\hline $\begin{array}{c}\text { Emotional } \\
\text { functioning }\end{array}$ & .04 & .02 & 4.60 & 1 & .03 & 1.04 & 1.00 & 1.08 \\
\hline
\end{tabular}

Year $5(n=167)$

\begin{tabular}{|c|c|c|c|c|c|c|c|c|}
\hline $\begin{array}{c}\text { Cognitive } \\
\text { functioning }\end{array}$ & .06 & .03 & 4.20 & 1 & .04 & 1.06 & 1.00 & 1.21 \\
\hline
\end{tabular}

Goodness of fit $\mathrm{p}=<0.00$, Hosmer-Lemeshow Test $\mathrm{p}=>0.117$ $>0.483$.

The correlation between SOC-, QLQ - and, PR 25 scores were tested and showed various significant correlations at each data collection time point. Variables with significant correlations were used as independent variables in the logistic regression analysis per each data collection time point.

Results from the logistic regression analysis (Table 2,3) showed that the likelihood of scoring a high SOC was associated with psychosomatic variables (emotional-, cognitive-, social functioning as well as global quality of life) at all 5 data assessment time points, together with fatigue, even though not always significant. At three months emotional functioning $(\mathrm{p}=<0.01)$, quality of life $(\mathrm{p}=<0.00)$ and economy $(\mathrm{p}=<0.03)$ scored significantly while physical post-surgery conditions, such as urinary and sexual functioning, pain, hormonal treatment related problems and insomnia, were associated to SOC first at 1 year and later (ns). The index of roll functioning was significantly associated with SOC in year 3 $(\mathrm{p}=<0.02)$.

Table 3. Significant impact from high SOC on QLQ and PR 25 functional indexes and single item at time point of data collection

\begin{tabular}{|c|c|c|c|c|c|}
\hline Month/ Year & 3 months & 1 & 2 & 3 & 5 \\
\hline Emotional & $\mathrm{x}$ & $\mathrm{x}$ & $\mathrm{x}$ & $\mathrm{x}$ & \\
\hline Cognitive & & & & & $\mathrm{x}$ \\
\hline Social & & & & & \\
\hline QoL & $\mathrm{x}$ & $\mathrm{x}$ & & & \\
\hline Fatigue & & & & & \\
\hline Role & & & & $\mathrm{x}$ & \\
\hline Economy & $\mathrm{x}$ & & & & \\
\hline Pain & & & & & \\
\hline Insomnia & & & & & \\
\hline Urinary & & & & & \\
\hline Sexual funct. & & & & & \\
\hline Hormone rel. & & $\mathrm{x}$ & & & \\
\hline
\end{tabular}

High SOC was not associated with the few urinary- and sexual functioning related problems (ns). At 5 years the one remaining contribution from high SOC on quality of life scores was cognitive functioning $(\mathrm{p}=<0.04)$. 
Discussion

Few studies have reported on a 5 year longitudinal follow up after radical prostatectomy with $\mathrm{SOC}$ as a positive predictor for quality of life outcome. Hence, our study shows important implications for the clinical and post-surgery treatment years. In our study, at 5 years, most of the participants remained in the study showing a high compliance with completion of all data collection times and the fidelity to the study. We interpret the results as indicating that the questionnaires were understandable and easy to fill in. There are limitations to self-reported questionnaire studies in terms of validity and reliability. However, the validity in this study was considered high since there were few internal drop outs and a high participation rate after five years. The reliability is strengthened by the use of well reputed instruments with reported high internal consistency. Also, the study was designed and the data analysed by researchers with experience of using and statistically analysing the questionnaires.

In the analysis we used a positive odds ratio for reporting the likelihood of a high sense of coherence associated with various quality of life outcomes. This approach is in line with the underlying theoretical assumptions of salutogenesis and highlights a person's positive health opinion rather than a negative one. The analysis showed that the participant's high level of SOC was mostly connected to psychological aspects and that known post-surgery physical complications did not affect SOC levels to an extent that affected meaningfulness, comprehensibility and manageability in their lives. High SOC contributed to a low level of emotional problems (i.e. they did not feel tense, irritated or depressed) throughout the study. During the 5 years of data collection, cognitive functioning (concentrating and remembering) was rated as more important.

Surprisingly the emotional and cognitive functioning stood out as being most likely to be connected to SOC over the study period. On one hand we expected physical problems such as pain, urinary and sexual problems to be dominant, at least during the early part of the recovery period. On the other hand this might not be surprising at all since SOC in its self as it appears measure psychological aspects of life and not physical problems. However, Antonovsky describes that the SOC scale is for measuring both aspects, which was the base for this study. This finding implies the need for early post-surgery emotional and cognitive support from health care providers both at out-patient care and at in-hospital care [8].

There are few studies made with SOC as a positive denominator for quality of life from both physical and psychological aspects therefore there are few possibilities to compare our results. The importance of emotional functioning for daily life comfort is also often described elsewhere in an inverted way, i.e. as emotional distress. Orom et al. (2015) describe the matter in this way in their study $(n=1575)$ of men newly diagnosed with prostate cancer. They note how emotional distress such as a low grade of resilience and optimism affected men's lives and ability to recover from stress [19]. Ezer et al. found how, after 18 months (2012) in 81 men, (at first data collection) after various treatments SOC was connected to psychological distress, i.e. low SOC which resulted in a lot of problems [20]. Contradicting our results is an Italian study of patients with Parkinson's disease (2014) and while naturally there is a difference between the diseases' manifestation, revealed correlation and regression analysis, there was no connection between SOC and emotional distress [21]. The authors of the Italian study took a societal grip into their interpretation and explained their result for emotional distress by the strained economic situation in Italy and that people had less good prospects than they had a couple of years previous. This standpoint is interesting and would benefit the interpretation of other studies. In our study economic distress was found at three months which we interpret to be a sign of worry about having to take sick leave and thereby having less money to live on after having been given a cancer diagnosis while still in paid employment, more so than over a society in economic predicament. The effect of economics in the study was not noted during the following years of investigation thereby underpinning that suggestion.

Whether the result of cognitive function is connected with general decline in the ability to remember and concentrate or actually has to do with treatment and its side effects are not within the aim of the study. In our study hormone presurgical treatment is not assessed, nevertheless it is a common treatment option pre-operatively. Among several others, Gonzales et al. (2015) found impaired cognitive functioning in men having androgen deprivation therapy, ADT, after 12 months [22]. Also Mandelblatt et al. (2014) described this fact and called for a narrow follow up of older patients going through ADT in order do no more harm than necessary to the life quality of these patients. There is no consensus on why and how ADT affects cognitive functioning, which calls for further research and a specific reliable assessment instrument [23]. It is logical to assume that the results from our study might be a mix of therapy consequences and old age, in which case the preserved ability to function cognitively appears to be important.

Quality of life, as an index, was connected to high SOC at an early stage post treatment but not later on. This is found also in a previous study by Jakobsson et al. (2013) of men 3 years after diagnosis [10]. It is reasonable to interpret that health in general and life quality are perceived as being threatened at the beginning of a cancer treatment period and that later on other more detailed aspects of life quality are considered to be more specifically important.

The appearance of low amount of hormone related symptoms being associated with SOC in year 1 of data collection requires explanation. Physiologically there may well have been swollen limbs and weight loss/gain given as a natural cause in older men; however, we interpret perceived manhood as the dominant in this index. It is well-known how surgery and treatment affects manhood and sexual functioning. Deteriorating manhood, manifested as sexual problems, is described among others by Sveistrup et al. in men with e.g. ADT [24]. Fransson and Widmark also found profound deterioration in erectile- and sexual activity after 15 years [25]. We suggest that the men's perceived manhood was not inflicted in the beginning of the recovery period, this may be connected to a gratitude for early radical treatment and good prospect of survival and for the future. Our study goes back over 5 years and it would be interesting to see results from even a later follow up.

Role functioning, as the ability to function in daily life activities, was associated with high SOC in year 3. Another Swedish study of 6003 men at a 12 years follow up by Carlsson et al. (2015) found 
long term impacts on functional outcomes after various treatments, such as bowel,- and urinary problems and sexual dysfunction. Daily life activities may be defined as other aspects than these, but with evidence based results at hand it is logical to assume that the aspects are highly relevant for men with prostate cancer and affects their daily life activities [26].

\section{Conclusion}

Our study manages to show the importance of high Sense of Coherence as a health resource for experiencing quality of life after PC treatment. The result also shows stability in scoring over 5 years. In this longitudinal follow up high sense of coherence was associated merely to psychological aspects of life quality rather than physical and treatment side effects. The study results build on knowledge of daily life consequences after prostate cancer treatment with implications for clinical practice and post treatment rehabilitation and imply the need for not only physical support but also early and continuous emotional and psychological support from health care providers.

\section{Acknowledgement}

We express our gratitude to all men participating in the study from baseline to 5 years post-surgery.

\section{References}

1. Hjälm-Eriksson $\mathrm{M}$, Lennernäs $\mathrm{B}$, Ullén $\mathrm{A}$, Johansson $\mathrm{H}$, Hugosson J, et al. (2015) Long-term health-related quality of life after currative treatment for prostate cancer: A regional cross-sectional comparison of two standard treatment modalities. International Journal of Oncology 46: 381-388.

2. Jakobsson L (2002) Indwelling catheter treatment and health-related quality of life in men with prostate cancer in comparison with men with benign prostatic hyperplasia. Scandinavian Journal of Caring Sciences 16: 264-271.

3. Moksnes U, Løhre A and Espnes G (2012) the association between sense of coherence and life satisfaction in adolescentss. Quality of Life Research 22: 1331-1338.

4. Bill-Axelsson A, Holmberg L, Garmo H, Jennifer R. Rider ScD, Kimmo Taari MD, et al. (2014) Radical Prostateectomy or Watchful Waiting in Early Prostate cancer. The New England Journal of Medicin 370: 932-942.

5. Socialstyrelsen (2014) Cancer Incidence in Sweden 2013. Stockholm: Allmänna förlaget.

6. Nilsson B, Holmgren L, Westman G (2000) Sense of coherence in different stages of health and disease in northern Sweden -gender and psychosocial differences. Scandinavian Journal of Primary Health Care 18: 14-20.

7. Borglin G, Jakobsson U, Edberg AK, Hallberg IR (2006) Older people in Sweden with various degrees of present quality of life: their health, social support, everday activities and sense of coherence. Health and Social Care in the Community 14: 136-146.

8. Antonovsky A (1996) the salutogenic model as a theory to guide health promotion. Health Promotion International 11: 11-18.

9. Antonovsky A (1987) Unravelling the mystery of health: How people manage stress and stay well. San Francisco: JosseyBass.

10. Jakobsson L, Persson L and Lundqvist P (2013) Daily life and life quality 3 years following prostate cancer treatment. BMC Nursing 12: 11.

11. Antonovsky A (1993) the structure and properties of the sense of coherence scale. Soc Sci Med 36: 725-733.

12. Aaronson NK, Ahmedzai S, Bergman B, Bullinger M, Cull
A, et al. (1993) The European Organisation for Research and Treatment of Cancer QLQ C-30: A quality-of-life instrument for use in international clinical trials in oncology Journal of the National Cancer Institute 85: 365-376.

13. Van Andel G, Bottomley A, Fosså SD, Efficace F, Coens C, et al. (2008) An international field study of the EORTC QLQPR25: A questionnaire for assessing the health-related quality of life of patients with prostate cancer. European Journal of Cancer 44: 2418-2424.

14. Fayers PM, Aaronson NK, Bjordal K (2001) The EORTC QLQ-C30 Scoring Manual 3rd Ed. European Organisation for Research and Treatment of Cancer.

15. Pallant J. SPSS. Survival Manual (2013) UK: McGraw-Hill Education.

16. Altman DG. Practical statistics for medical research. London: Chapman \& Hall, 1997.

17. Warner RM. Applied statistics (2008) from bivariate through munltivariate techniques. USA: Sage Publications, 2008.

18. Jakobsson L and Fransson P (2013) Patient reported outcome measure (PROM) of quality of life after prostatectomy - results from a five-year study. Scores from the EORTC QLQ-C30 and PR 25 questionnaires The Open Nursing Journal 7: 165-173.

19. Orom H, Nelson CJ, Underwood III W, Homish DL, Kapoor DA (2015) Factors associated with emotional distress in newly diagnosed prostate cancer patients. Psycho-Oncology 24: 1416-1422.

20. Ezer H, Rigol Chachamovich J, Saad F, Aprikian A, Souhami L (2012) Psychological adjustment of men during the first year of prostate cancer. Cancer Nursing 35: 141-147.

21. Gison A, Rizza F, Bonassi S, Dall'Armi V, Lisi S, et al. (2014) The sense of coherence predicts health-rated quality of life and emotional distress but not disability in Parkinson's disease. BMC Neurology 14: 193.

22. Gonzalez BD, Jim HS, Booth-Jones M, Small BJ, Sutton SK, et al. (2015) Course and Predictors of Cognitive Function in Patients With Prostate Cancer Receiving AndrogenDeprivation Therapy: A Controlled Comparison. Journal of Clinical Oncology 33: 2021-2027.

23. Mandelblatt JS, Jacobsen PB, Ahles T (2014) Cognitive Effects of Cancer Systemic Therapy: Implications for the Care of Older Patients and Survivors. Journal of Clincal Oncology 2014. 32: 2617-2626.

24. Sveistrup J, Widmark A, Fransson P, Peter Iversen, Munck Af Rosenschold, et al. (2015) Prospective assessment of urinary, gastrointestinal and sexual symptoms before, during and after image-guided volumetric modulated arc therapy for prostate cancer. Scandinavian Journal of Urology 49: 58-69.

25. Fransson P and Widmark A (2009) Does one have sexual life 15 years after external beam radiotherapy for prostate cancer? Prospective patient-reported outcome of sexual function comparison with age-matched controls. Urologic Oncology 29: 137-144.

26. Carlsson S, Drevin L, Loeb S, Anders Widmark, Ingela Franck Lissbrant, et al. (2015) Population-based study of long-term functional outcomes after prostate cancer treatment. BJU International 117: E36-E45.

Copyright: (c)2017 Liselotte Jakobsson et al. This is an open-access article distributed under the terms of the Creative Commons Attribution License, which permits unrestricted use, distribution, and reproduction in any medium, provided the original author and source are credited. 